\title{
Heating Experiment of CNT Cementitious Composites with Single-Walled and Multiwalled Carbon Nanotubes
}

\author{
Heeyoung Lee, ${ }^{1}$ Donghoon Kang, ${ }^{2}$ Young Min Song, ${ }^{1}$ and Wonseok Chung ${ }^{1}$ \\ ${ }^{1}$ Kyung Hee University, Seoul, Republic of Korea \\ ${ }^{2}$ Korea Railroad Research Institute, Gyeonggi-do, Republic of Korea \\ Correspondence should be addressed to Wonseok Chung; wschung@khu.ac.kr
}

Received 28 February 2017; Revised 27 April 2017; Accepted 3 May 2017; Published 29 May 2017

Academic Editor: Lili Zhang

Copyright (c) 2017 Heeyoung Lee et al. This is an open access article distributed under the Creative Commons Attribution License, which permits unrestricted use, distribution, and reproduction in any medium, provided the original work is properly cited.

\begin{abstract}
Carbon nanotubes (CNTs) are a primary nanomaterial that have outstanding physical and mechanical characteristics, and CNTs can be combined with cement-based materials to alter their heating characteristics. In this study, the types of CNTs used were multiwalled carbon nanotubes (MWCNTs) and single-walled carbon nanotubes (SWCNTs). Experiments were performed to determine the altered heating characteristics of the CNT cement mortars. The parameters of the experiment were CNT type, CNT content, curing age, and applied voltage. The results for the different CNT cement mortars indicate that mixing SWCNTs with water to produce CNT cement mortars was more effective for modifying the heating characteristics compared to mixing MWCNTs with water. In addition, field emission scanning electron microscope (FE-SEM) images supported the results found in the heating experiments.
\end{abstract}

\section{Introduction}

Recently, various functionalization studies on the combination of cement-based materials with nanomaterials have been carried out for diverse purposes. In particular, nanotechnology has become important in various different areas. This is especially true in the fields of machinery and aerospace, where cutting-edge nanotechnology is being used to develop mechanically stronger and functionally new materials. Specifically, research is being performed that improves the physical and mechanical characteristics of cement-based materials through the use of nanomaterials, providing the former with new functions. However, the multifunctionalization of construction materials with nanotechnology still remains a challenge. Thus, experimental research is needed regarding new materials created through the convergence of nanotechnology and construction materials, which may result in a wide range of functions.

The kinds of carbon allotropes that are found in nature include graphite, graphene, and carbon nanotubes (CNTs). CNTs were first observed in the form of multiwalled carbon nanotubes (MWCNTs) when examining carbon by-products found on graphite electrodes in Japan [1]. Afterwards, it became possible to produce single-walled carbon nanotubes (SWCNTs) through the use of catalysts [2]. CNTs are characterized by lower densities and larger length to diameter ratios compared to other carbon allotropes. The electrical conductivity of CNTs is largely similar to that of copper $(5.81 \times 107 \mathrm{~s} / \mathrm{m})$, while the heat conductivity of CNTs is the same or higher than that of diamonds $(3,320 \mathrm{~W} / \mathrm{m} \cdot \mathrm{k})$. Moreover, the electrical conductivity of CNTs can be controlled to be either semiconductors or conductors, depending on the diameter and structure of the CNTs, and CNTs are more than 100 times stronger than structured steel under the same conditions. Under certain modifications, CNTs have a piezo-resistive effect, enabling self-measuring functions. The electrical characteristics of CNTs are due to their linear, onedimensional structure and inherent electrical characteristics, including their very low electrical resistance.

CNTs are classified as MWCNTs and SWCNTs depending on the number of carbon walls inside of the tube, as shown Figure 1. The mechanical strength, electrical conductivity, and heat conductivity of CNTs differ according to the type of CNT [3]. Some researchers have investigated the sensing functions of conductive cement composites after the addition of CNTs [4-6]. Table 1 compares the mechanical and physical 
TABLE 1: Mechanical and physical characteristics of the MWCNTs and SWCNTs.

\begin{tabular}{|c|c|c|c|}
\hline & MWCNT & SWCNT & Notes \\
\hline \multirow{2}{*}{ Structure } & Diameter: 5-100 nm & Diameter: $0.5-3.0 \mathrm{~nm}$ & \multirow{2}{*}{-} \\
\hline & Length: $100 \mathrm{~nm}-1 \mathrm{~cm}$ & Length: $100 \mathrm{~nm}-1 \mathrm{~cm}$ & \\
\hline Modulus of elasticity & $0.3-0.95 \mathrm{TPa}$ & $1.0-5.0 \mathrm{TPa}$ & $\begin{array}{c}0.1-0.14 \mathrm{TPa} \\
\text { (Cement mortar) }\end{array}$ \\
\hline Tensile strength & $11-63 \mathrm{GPa}$ & $13-53 \mathrm{GPa}$ & $\begin{array}{c}\text { 0.002-0.01 GPa } \\
\text { (Cement mortar) }\end{array}$ \\
\hline Density & $1.6 \mathrm{~g} / \mathrm{cm}^{3}$ & $1.33-1.40 \mathrm{~g} / \mathrm{cm}^{3}$ & $\begin{array}{c}2.7 \mathrm{~g} / \mathrm{cm}^{3} \\
(\mathrm{Al})\end{array}$ \\
\hline Electrical conductivity & $\sim 6,000 \mathrm{~S} / \mathrm{cm}$ & $\sim 10,000 \mathrm{~S} / \mathrm{cm}$ & $\begin{array}{c}5,810 \mathrm{~S} / \mathrm{cm} \\
(\mathrm{Cu})\end{array}$ \\
\hline Heat conductivity & Max. $3,000 \mathrm{~W} / \mathrm{m} \cdot \mathrm{k}$ & Max. $6,000 \mathrm{~W} / \mathrm{m} \cdot \mathrm{k}$ & $\begin{array}{c}3,320 \mathrm{~W} / \mathrm{m} \cdot \mathrm{k} \\
\text { (Diamond) }\end{array}$ \\
\hline
\end{tabular}

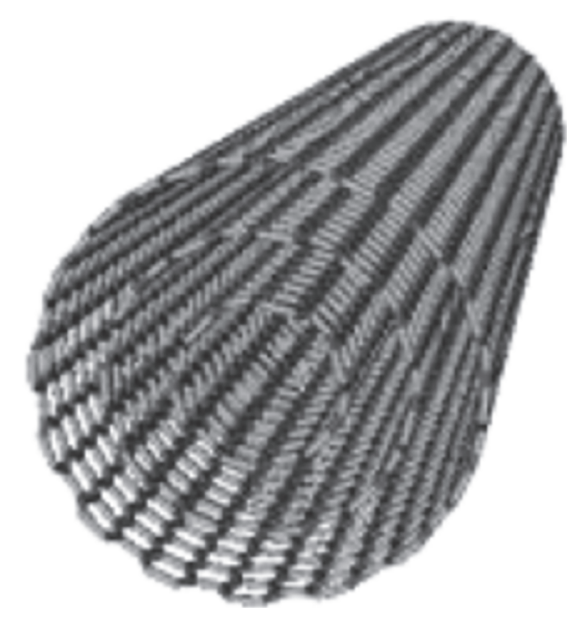

(a) Multiwalled carbon nanotubes (MWCNTs)

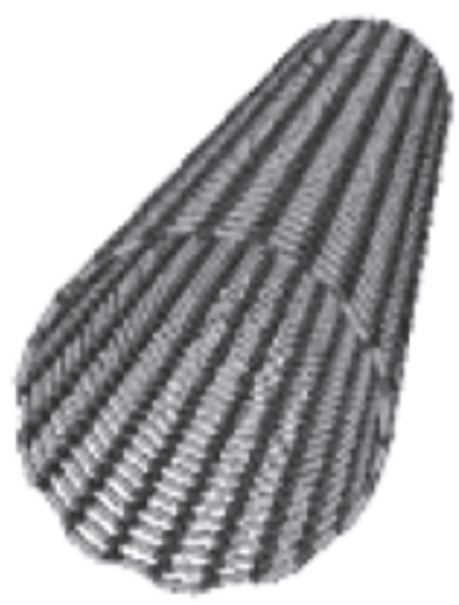

(b) Single-walled carbon nanotubes (SWCNTs)

Figure 1: Structure of the CNTs.

characteristics of MWCNTs and SWCNTs with those of construction materials [7]. SWCNTs have a higher elastic modulus, tensile strength, and heat conductivity compared to MWCNTs; however, the production of SWCNTs is difficult, making mass production rare. MWCNTs have inferior characteristics compared to SWCNTs, but have superior mechanical and physical characteristics when compared to other nanomaterials. Moreover, MWCNTs are comparatively cheaper and easier to produce, and they also have a higher dispersibility, giving them several advantages from an industrial viewpoint and thus making them more suitable for mixing with cement-based materials. Therefore, most studies have examined cement mortar mixed with MWCNTs. However, SWCNTs have excellent mechanical and physical characteristics, and so their industrial value would become higher if mass production ever became possible. Hence, this study also includes results regarding SWCNTs, in particular results regarding their heating characteristics. This study determines whether the heating characteristics of CNT cement mortars change if SWCNTs are mixed in at low contents, as is the case with MWCNTs.
A large number of experimental studies on the mixing of nanomaterials and cement mortars to improve the mechanical strength of the latter have been conducted [8-16]. A study by Seo on improving the mechanical strength of nanocement mortars involved mixing with a MWCNT solution, where compressive strength experiments were conducted with MWCNT cement mortars. These test results showed that the compressive strength of all MWCNT cement mortars was higher than that of normal cement mortar. Further, this study demonstrated that the MWCNTs were distributed in a net-like fashion between the hydration material, acting as a bridge for the microscopic cracks in the cement [17]. Choi et al. conducted compressive strength experiments for MWCNT cement mortars containing an MWCNT solution. The diluted $0.5 \mathrm{wt} \%$ MWCNT solution utilized in their study was made with $1.0 \mathrm{wt} \%$ and $0.75 \mathrm{wt} \%$ MWCNT solutions and distilled water. The study concluded that dilution of the MWCNT solution did not heavily influence the condensation or dispersion of the solution [18]. Camacho et al. evaluated the compressive and flexural strength of CNT cement mortars, using the CNT content as a parameter. Their study 
verified that once the CNT solution content was over $0.05 \%$, the compressive and flexural strength of the CNT cement mortar began to decline [19]. Kang and Park investigated the microscopic structure of a cement mortar mixed with MWCNTs using a scanning electron microscope (SEM) and $\mathrm{X}$-ray diffraction (XRD). The results showed that the addition of CNTs led to minimal changes in the hydration products within the cement mortar [20].

Recently, studies focusing on modifying the electrical and heat conductivities of nano-cement mortars have been growing in number. Gomis et al. examined the heat conductivities of various nano-mixed specimens, with the water/cement mix ratio, contents of nanomaterials, and supplied electricity $(50 \mathrm{~V}, 100 \mathrm{~V}$, and $150 \mathrm{~V})$ as the parameters. This study concluded that supplying electricity to the CNT cement mortar resulted in thawing effects in terms of the transportation infrastructure structure [21]. Zhao et al. utilized a concrete slab with carbon fiber heating wires (CFHWs) to study such thawing methods; the results showed that the method utilizing CFHWs in slabs was good for thawing ice on top of the slab [22]. Chung investigated cement polymers in order to increase the heat resistance of cement for thawing and heating purposes. The heat resistance of cement can be increased by mixing electricity-conducting fibers with cement. The test results demonstrated that a cement polymer with a carbon fiber mat is the most effective structure for self-heating, with the exception of flexible graphite [23]. Han et al. evaluated the electricity resistance of MWCNT cement mortars subjected to repetitive compressive loads for a wide range of water contents $(0.1 \%, 3.3 \%, 5.7 \%, 7.6 \%$, and $9.9 \%)$. The test results indicated that the piezo-resistance of a MWCNT cement mortar is closely related to its internal water content [24]. Han et al. investigated $50 \times 50 \times 50 \mathrm{~mm}^{3} \mathrm{CNT}$ cement mortars via a basic experiment in order to produce a self-diagnosis of concrete structure. Their study proposed a standard method for both embedding steel nets inside CNT cement mortars and acquiring data while under the influence of a power supply. Compressive strength-resistance tests were performed using specimens with two steel nets inserted into them. These test results suggested that the electrical resistance of a CNT cement mortar is directly correlated with the compressive load [25]. Zhang and Li examined thawing systems for MWCNT cement pavements. A heat conducting layer with a heat conductivity of $2.83 \mathrm{~W} / \mathrm{m} \cdot \mathrm{K}$ was produced by mixing $3 \mathrm{wt} \% \mathrm{MWCNTs}$ with cement. This study concluded that thawing systems could be constructed using MWCNT-mixed cement structures with an applied electricity [26]. Kim et al. studied the mechanical and physical characteristics of a CNT cement mortar with silica fumes. SEM images of the specimens showed that the addition of silica fumes increased the contact interface between the CNTs and hydration products, thus improving the dispersibility of CNTs [27].

The purpose of the present study is to experimentally analyze the heating characteristics of CNT cement mortars produced by mixing different types of CNTs with cement. The heating characteristics of CNT cement mortars vary depending on the type of CNT used when mixing with cement. The two types of CNT cement mortars used in this experiment are

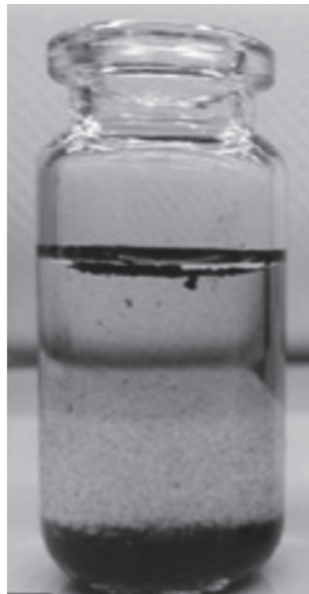

(a) Undispersed CNT solution

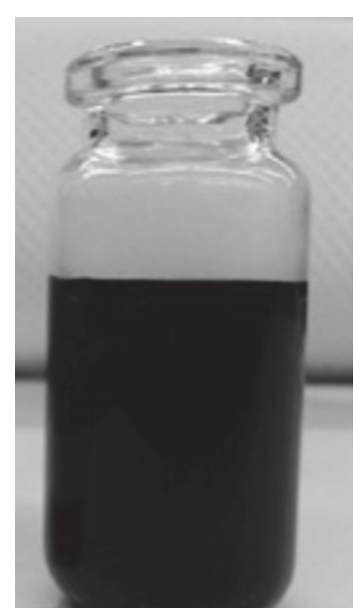

(b) Dispersed CNT solution
Figure 2: Disperse CNT solutions.

MWCNT cement mortars, produced by mixing MWCNTs with cement, and SWCNT cement mortars, produced by mixing SWCNTs with cement. We measured the internal temperature variations by considering their resistance to heating, which was accomplished by supplying electricity to the CNT cement mortars with varying parameters. The key parameters of this experiment were the CNT type, CNT content, curing age, and supplied voltage. The heating characteristics of the CNT cement mortars are analyzed by measuring the variations in temperature. The main objective of this study was to identify the heating characteristics of the CNT cement mortars by comparing the dispersibility of MWCNTs and SWCNTs within the cement mortars. The secondary objective was to analyze the heating characteristics of CNT cement mortars depending on the CNT content, curing age, and voltage of the supplied electricity.

\section{Experimental Program}

The contents of the mixed CNTs are $0.0625 \%$ and $0.125 \%$, as a percent of the cement weight. Because the van der Waals (vdW) force is present between the carbon particles in CNTs, cohesion occurs when it is mixed in a solution, as shown Figure 2(a). To produce an evenly dispersed CNT solution, a combination of chemical and physical methods was utilized. For these solutions, surfactants were applied, which then underwent ultrasonic processing. Figure 2(b) shows an evenly dispersed CNT solution [28].

Table 2 shows the specific characterizations of MWCNTs and SWCNTs. The MWCNTs were manufactured via the catalytic chemical vapor deposition (CCVD) process using a NANOCYL NC7000 ${ }^{\mathrm{TM}}$ (NANOCYL SA, Belgium). The carbon purity was $90 \%$, the average diameter was $9.5 \mathrm{~nm}$, and the average length was $1.5 \mu \mathrm{m}$. MWCNTs are tube-shaped materials with a nanometric diameter that are exclusively composed of carbon atoms. The graphite layer can be visualized as rolled-up chicken wire with a continuous, unbroken hexagonal mesh, with carbon atoms placed at the vertices 
TABLE 2: Specific characterization of CNTs.

\begin{tabular}{lcccc}
\hline Type of CNT & Properties & Unit & Value & Method of measurement \\
\hline \multirow{4}{*}{ MWCNTs } & Average diameter & $10^{-9}$ & 9.5 & Transmission electron microscopy (TEM) \\
& Average length & $\mu \mathrm{m}$ & 1.5 & Transmission electron microscopy (TEM) \\
& Carbon purity & $\%$ & 90 & Thermogravimetric analysis (TGA) \\
& Transition metal oxide & $\%$ & $<1 \%$ & Inductively coupled plasma mass spectrometry (ICP-MS) \\
& Amorphous carbon & - & $*$ & High resolution transmission electron microscopy (HRTEM) \\
& Surface area & $\mathrm{m} / \mathrm{g}$ & $250-300$ & BET surface area analysis \\
SWCNTs & Volume resistivity & $\Omega$ & $10^{-4}$ & Internal test method (resistivity on powder) \\
& Average diameter & $10^{-9}$ & $1.8 \pm 0.3$ & Transmission electron microscopy (TEM) \\
& Average length & $\mu \mathrm{m}$ & $>5$ & Transmission electron microscopy (TEM) \\
& Carbon purity & $\mathrm{wt} . \%$ & $>85$ & Thermogravimetric analysis (TGA) \\
& Volume resistivity & $\Omega$ & $10^{-8}-10^{-2}$ & Internal test method (resistivity on powder) \\
\hline
\end{tabular}

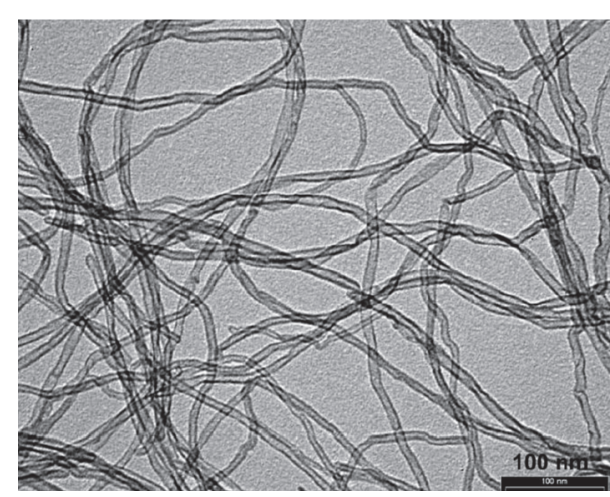

(a) MWCNTs

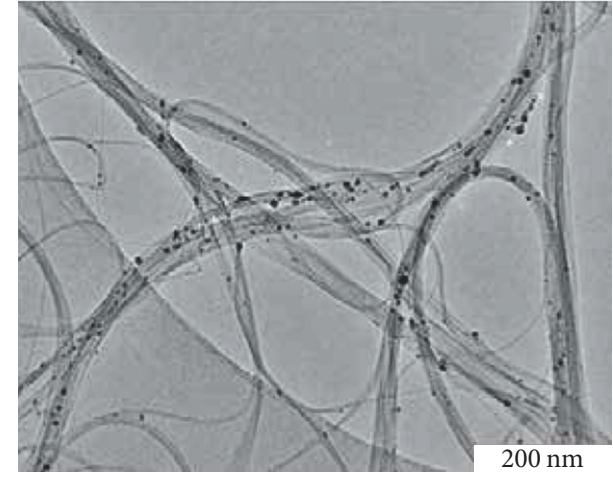

(b) SWCNTs

Figure 3: TEM images of the two CNT types.

of the hexagons. With the presence of van der Waals forces, MWCNTs have a tendency to cluster into bundles or agglomerates. Consequently, the MWCNTs look like a black powder. At the nanoscale, MWCNTs have a spaghetti-like structure. Figure 3(a) shows TEM images of the MWCNTs. The SWCNTs used in this study were a new type of material manufactured via the chemical vapor deposition (CVD) process using TUBALL (OCSiAl Ltd.). The carbon purity was more than $85 \%$, the average outer mean diameter was $1.8 \pm 0.3 \mathrm{~nm}$, and the average length was more than $5 \mu \mathrm{m}$. Figure 3(b) shows TEM images of the SWNTs.

For our heating experiment, we measured changes in the internal temperature of the CNT cement mortars, considering the CNT type, CNT content, curing age, and supplied voltage as the parameters. The specimens were manufactured utilizing the two CNT types mentioned above. The first specimen was produced by mixing the MWCNT-water solution with cement and sand ("MWCNT cement mortar" hereafter), while the second specimen was produced by mixing the SWCNT-water solution with cement and sand ("SWCNT cement mortar" hereafter). Three specimens for each type and each parameter were manufactured to accurately measure changes in the internal temperature when electricity was supplied. In this study, the specimens were the same size as those used in the compressive strength experiments of a previous study; that is, the three specimens were in accordance with the KS L ISO 679 regulations [29]. The average value of the variation in internal temperature was used as the mean value for each parameter.

Table 3 shows the parameters for the different nanocement mortars. The specimens were grouped according to production method. Group 1 is the control group with the standard cement mortar, Group 2 consists of the MWCNT cement mortars, and Group 3 corresponds to the SWCNT cement mortars. The CNT contents in Group 2 were $0.0625 \mathrm{wt} \%$ and $0.125 \mathrm{wt} \%$, allowing for comparisons with the SWCNT cement mortars. The curing ages of the cement mortars in all groups were classified as 7 or 28 days, and the supplied electricity was divided into $50 \mathrm{~V}$ and $100 \mathrm{~V}$.

The first few characters of each specimen name indicate the used material. Specifically, "OPC" (ordinary Portland cement) refers to the standard cement mortar, "MW" refers to the MWCNT cement mortar, and "SW" refers to the SWCNT cement mortar. The second group of characters in the specimen names, which is either " 00625 " or " 0125 ", refers to the content of the CNTs as the percentage of cement weight, that is, $0.0625 \mathrm{wt} \%$ and $0.125 \mathrm{wt} \%$, respectively. The last group of characters indicates to the curing age, with "7" indicating 7 days of curing and " 28 " indicating 28 days of curing. 
TABLE 3: The parameters of the CNT cement mortar heating experiments.

\begin{tabular}{|c|c|c|c|c|c|}
\hline Production method & Specimen name & CNT type & $\begin{array}{l}\text { CNT content } \\
(w \mathrm{t} \%)\end{array}$ & $\begin{array}{c}\text { Curing age } \\
\text { (days) }\end{array}$ & $\begin{array}{l}\text { Supplied voltage } \\
\text { (V) }\end{array}$ \\
\hline \multirow{4}{*}{ Group 1} & OPC-7-50 V & \multirow{4}{*}{-} & \multirow{4}{*}{ - } & \multirow{2}{*}{7} & 50 \\
\hline & OPC-7-100 V & & & & 100 \\
\hline & OPC-28-50 V & & & \multirow{2}{*}{28} & 50 \\
\hline & OPC-28-100 V & & & & 100 \\
\hline \multirow{8}{*}{ Group 2} & MW-0625-7-50 V & \multirow{8}{*}{ MWCNTs } & \multirow{4}{*}{0.0625} & \multirow{2}{*}{7} & 50 \\
\hline & MW-0625-7-100 V & & & & 100 \\
\hline & MW-0625-28-50 V & & & \multirow{2}{*}{28} & 50 \\
\hline & MW-0625-28-100 V & & & & 100 \\
\hline & MW-125-7-50 V & & \multirow{4}{*}{0.125} & \multirow{2}{*}{7} & 50 \\
\hline & MW-125-7-100 V & & & & 100 \\
\hline & MW-125-28-50 V & & & \multirow{2}{*}{28} & 50 \\
\hline & MW-125-28-100 V & & & & 100 \\
\hline \multirow{8}{*}{ Group 3} & SW-0625-7-50 V & \multirow{8}{*}{ SWCNTs } & \multirow{4}{*}{0.0625} & \multirow{2}{*}{7} & 50 \\
\hline & SW-0625-7-100 V & & & & 100 \\
\hline & SW-0625-28-50 V & & & \multirow{2}{*}{28} & 50 \\
\hline & SW-0625-28-100 V & & & & 100 \\
\hline & SW-125-7-50 V & & \multirow{4}{*}{0.125} & \multirow{2}{*}{7} & 50 \\
\hline & SW-125-7-100 V & & & & 100 \\
\hline & SW-125-28-50 V & & & \multirow{2}{*}{28} & 50 \\
\hline & SW-125-28-100 V & & & & 100 \\
\hline
\end{tabular}

The specimens were fabricated as $50 \times 50 \times 50 \mathrm{~mm}^{3}$ specimens with the water/cement ratio fixed at $0.5[30,31]$. Ordinary Portland cement (OPC) was used in the specimen production process, and the sand was standard sand as per the KS L ISO679 regulations. Tap water from the laboratory was used to produce the cement mortars. A thermocouple was utilized to measure the temperature at the center of the specimen, and $50 \times 70 \mathrm{~mm}^{2}$ steel nets were introduced into the specimens at $10 \mathrm{~mm}$ intervals. The CNT cement mortar was produced by dry-mixing cement and sand $(1: 2.5$ by weight) for two minutes using a mixer, as shown in Figure 4(a). The completed dry-mixes of cement and sand were placed in a mixer with the CNT solutions and mixed for two minutes. Figure 4(b) shows the mixing process for the CNT cement mortars. Specifically, the mortars were used to fill half of the mold and were compacted, followed by the insertion of two steel nets (Figure 4(c)). After the remainder of the mold was filled, the thermocouple was placed in the center, as shown in Figure 4(d). After the mold was compacted using a tamper, the remaining mortar that fell out was piled on top of the mold. After the deposition process, the mold was placed in a thermo-hygrostat for 24 hours, as shown in Figure 4(e). Figure 4(f) shows the underwater curing of the specimens in a tank with water. The specimens were cured in water and then completely dried.

Figure 5 shows the test setup. The specimens were first placed on rubber, as shown in Figure 5(a). Figure 5(b) shows the thermocouple inside one of the CNT cement mortars connected to the data logger. The steel nets within the CNT cement mortars were connected with a power supply, as shown in Figure 5(c). Finally, electricity was supplied to each specimen for 6,000 seconds and the temperature was measured. It should be noted that the ambient temperature was $15^{\circ} \mathrm{C}$.

\section{Experimental Results}

This study considered the CNT type, CNT content, curing age, and supplied voltage as the parameters and experimentally analyzed the heating characteristics of the CNT cement mortars. The maximum temperatures of the specimens were measured for each parameter, and the average values were used as reference for the temperature variations of the specimens $(\Delta T)$. Furthermore, this study also utilized field emission scanning electron microscopes (FE-SEM) to observe the inner cross-sections of the CNT cement mortars in order to analyze the inner temperature variations according to the CNT dispersion.

The results for the different CNT cement mortars are given in Table 4. In all cases, the temperature variations of the CNT cement mortars were higher than the temperature variations for OPC, regardless of the CNT type, CNT content, curing age, or supplied voltage.

Figure 6 shows the temperature-time curves under an applied electricity of $50 \mathrm{~V}$ cured for 7 days. When supplied with $50 \mathrm{~V}$ of electricity, the temperature variation of the standard cement mortar was $1.4^{\circ} \mathrm{C}$, while those of the $0.0625 \mathrm{wt} \%$ SWCNT and $0.0625 \mathrm{wt} \%$ MWCNT cement mortars were $34.3^{\circ} \mathrm{C}$ and $22.6^{\circ} \mathrm{C}$, respectively. Similarly, the temperature variation for the $0.125 \mathrm{wt} \%$ SWCNT cement 


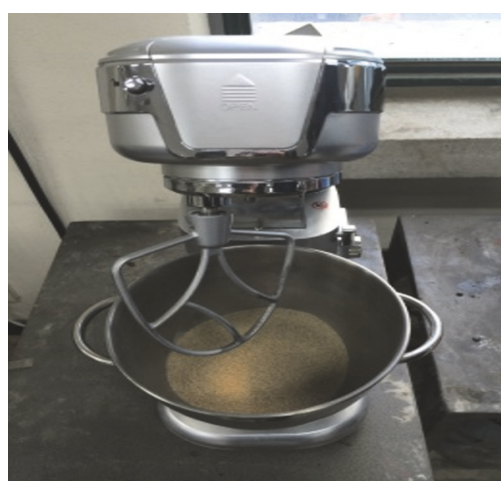

(a) Cement-sand dry mix

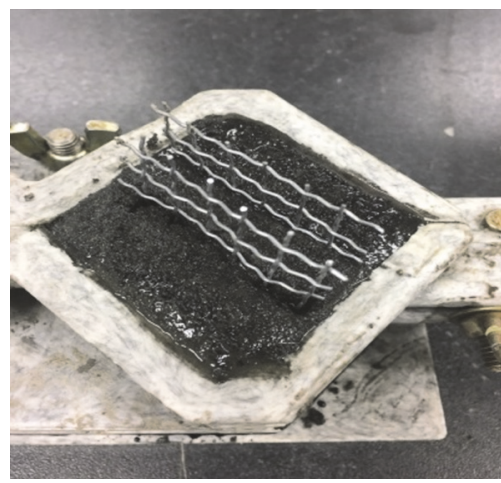

(c) Installing steel electrodes

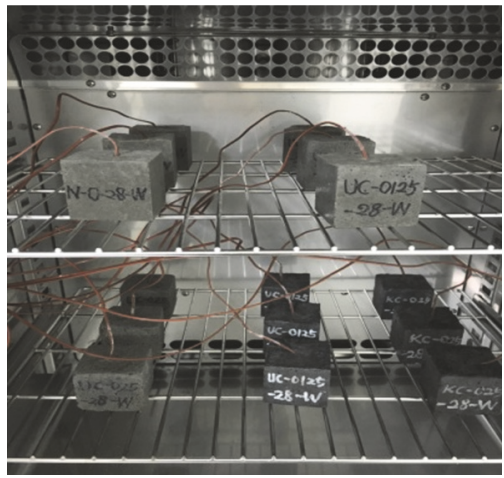

(e) Storage in the thermo-hygrostat

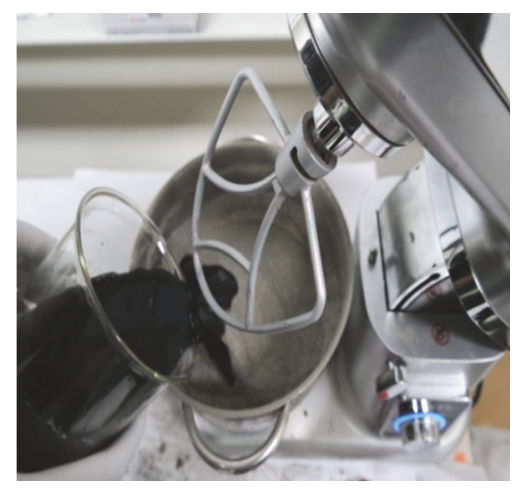

(b) CNT solution mixing

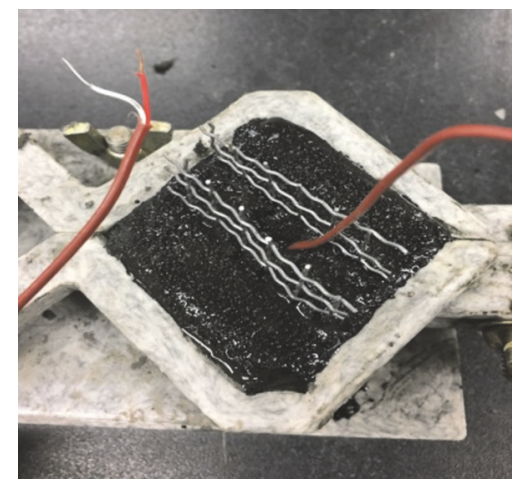

(d) Thermocouple insertion

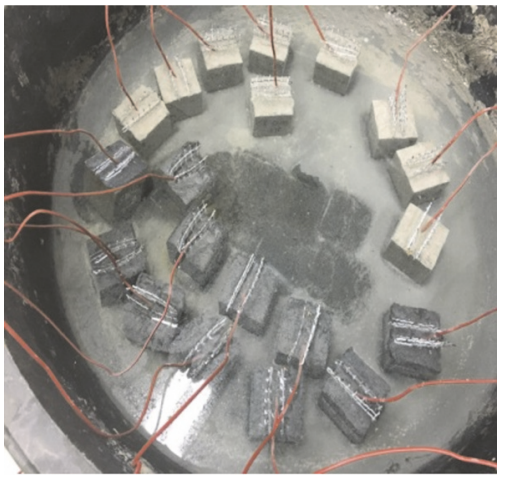

(f) Submerged curing

FigURE 4: Specimen production process.

mortar was $66.2^{\circ} \mathrm{C}$, while that for the $0.125 \mathrm{wt} \%$ MWCNT cement mortar was $33.3^{\circ} \mathrm{C}$. We found that mixing CNTs with the nonconductive standard cement mortar resulted in conductive characteristics. Moreover, noting that all the parameters were equal (apart from CNT type), the rise in temperature of the $0.0625 \mathrm{wt} \%$ SWCNT cement mortar was $151.8 \%$ higher than that of the $0.0625 \mathrm{wt} \%$ MWCNT cement mortar. In particular, the rise in temperature of the $0.125 \mathrm{wt} \%$ SWCNT cement mortar was $198.8 \%$ higher than that of the $0.125 \mathrm{wt} \%$ MWCNT cement mortar. It can be concluded that mixing SWCNTs with water improves the dispersibility of CNTs when compared to mixing MWCNTs with water, indicating the superior heating characteristics of SWCNTs.
Figure 7 shows the temperature-time curves under an applied electricity of $100 \mathrm{~V}$ cured for 28 days. When supplied with $100 \mathrm{~V}$ of electricity, the temperature variation of the normal cement mortar was $1.1^{\circ} \mathrm{C}$. The $0.0625 \mathrm{wt} \%$ SWCNT cement mortar had an increase in temperature of $56.8^{\circ} \mathrm{C}$, while that of the $0.0625 \mathrm{wt} \%$ MWCNT cement mortar was of $20.0^{\circ} \mathrm{C}$. Noting that all the parameters were equal (apart from CNT type), the rise in temperature of the $0.0625 \mathrm{wt} \%$ SWCNT cement mortar was $284.0 \%$ higher than that of the $0.0625 \mathrm{wt} \%$ MWCNT cement mortar. Similarly, the temperature variation for the $0.125 \mathrm{wt} \%$ SWCNT cement mortar was $65.3^{\circ} \mathrm{C}$, while that for the $0.125 \mathrm{wt} \%$ MWCNT cement mortar was $21.5^{\circ} \mathrm{C}$. In particular, the rise in temperature of the $0.125 \mathrm{wt} \%$ SWCNT 


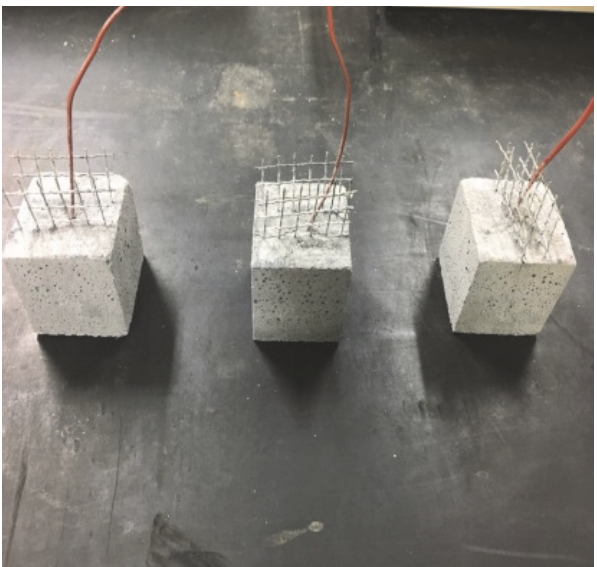

(a) Placing the specimens on insulating rubber

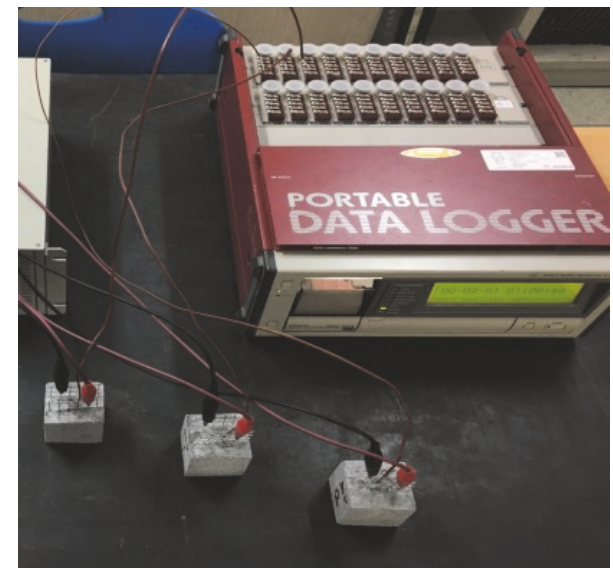

(b) Connecting the data logger with the specimens

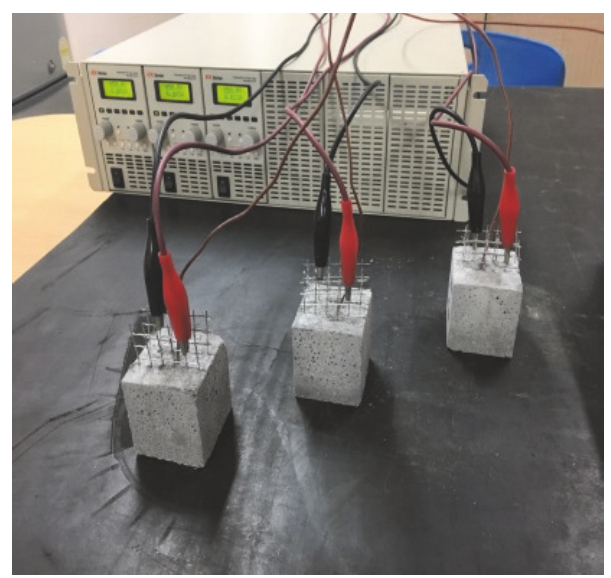

(c) Connecting the specimens with a power supply

FIGURE 5: Specimen installation.

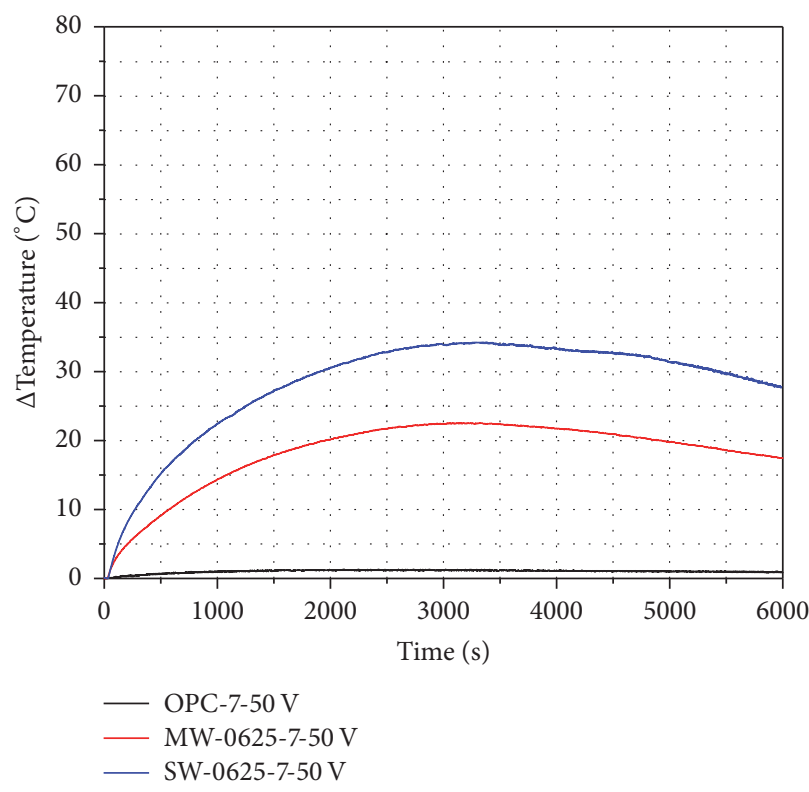

(a) $0.0625 \mathrm{wt} \%$ content

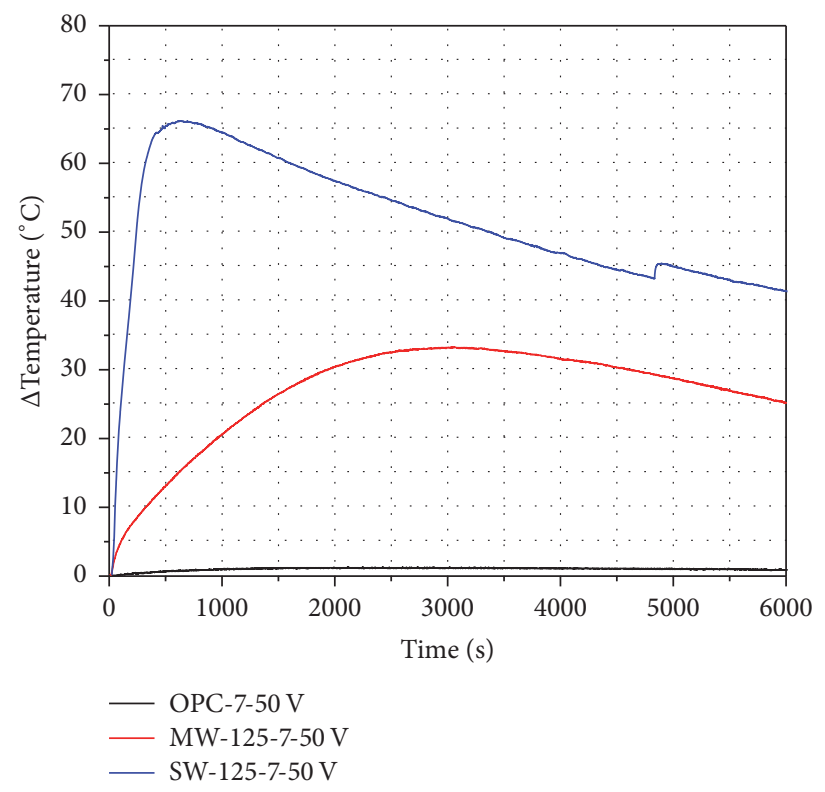

(b) $0.125 \mathrm{wt} \%$ content

FIgURE 6: Temperature variations for 7 days of curing and $50 \mathrm{~V}$ of electricity. 
TABLE 4: Heating experiment results for the CNT cement mortars.

\begin{tabular}{|c|c|c|c|c|c|c|}
\hline Specimen name & CNT type & $\begin{array}{c}\text { CNT content } \\
(\mathrm{wt} \%)\end{array}$ & $\begin{array}{c}\text { Curing age } \\
\text { (days) }\end{array}$ & $\begin{array}{c}\text { Supplied voltage } \\
(\mathrm{V})\end{array}$ & $\begin{array}{c}\text { Temperature } \\
\text { variation }\left({ }^{\circ} \mathrm{C}\right) \\
\end{array}$ & $\begin{array}{c}\text { Specimen/OPC } \\
\text { group }\end{array}$ \\
\hline OPC-7-50 V & \multirow{4}{*}{ - } & \multirow{4}{*}{ - } & \multirow{2}{*}{7} & 50 & 1.4 & - \\
\hline OPC-7-100 V & & & & 100 & 11.0 & - \\
\hline OPC-28-50 V & & & \multirow{2}{*}{28} & 50 & 0.5 & - \\
\hline OPC-28-100 V & & & & 100 & 1.1 & - \\
\hline MW-0625-7-50 V & \multirow{8}{*}{ MWCNTs } & \multirow{4}{*}{0.0625} & \multirow{2}{*}{7} & 50 & 22.6 & 16.1 \\
\hline MW-0625-7-100 V & & & & 100 & 43.7 & 4.0 \\
\hline MW-0625-28-50 V & & & \multirow{2}{*}{28} & 50 & 6.7 & 13.4 \\
\hline MW-0625-28-100 V & & & & 100 & 20.0 & 18.2 \\
\hline MW-125-7-50 V & & \multirow{4}{*}{0.125} & \multirow{2}{*}{7} & 50 & 33.3 & 23.8 \\
\hline MW-125-7-100 V & & & & 100 & 45.9 & 4.2 \\
\hline MW-125-28-50 V & & & \multirow{2}{*}{28} & 50 & 3.7 & 7.4 \\
\hline MW-125-28-100 V & & & & 100 & 21.5 & 19.6 \\
\hline SW-0625-7-50 V & \multirow{4}{*}{ SWCNTs } & \multirow{4}{*}{0.0625} & \multirow{2}{*}{7} & 50 & 34.3 & 24.5 \\
\hline SW-0625-7-100 V & & & & 100 & 59.1 & 5.2 \\
\hline SW-0625-28-50 V & & & \multirow{2}{*}{28} & 50 & 3.4 & 6.8 \\
\hline SW-0625-28-100 V & & & & 100 & 56.8 & 53.7 \\
\hline SW-125-7-50 V & \multirow{4}{*}{ SWCNTs } & \multirow{4}{*}{0.125} & \multirow{2}{*}{7} & 50 & 66.2 & 47.4 \\
\hline SW-125-7-100 V & & & & 100 & 70.6 & 5.9 \\
\hline SW-125-28-50 V & & & \multirow{2}{*}{28} & 50 & 5.0 & 10 \\
\hline SW-125-28-100 V & & & & 100 & 65.3 & 64.2 \\
\hline
\end{tabular}

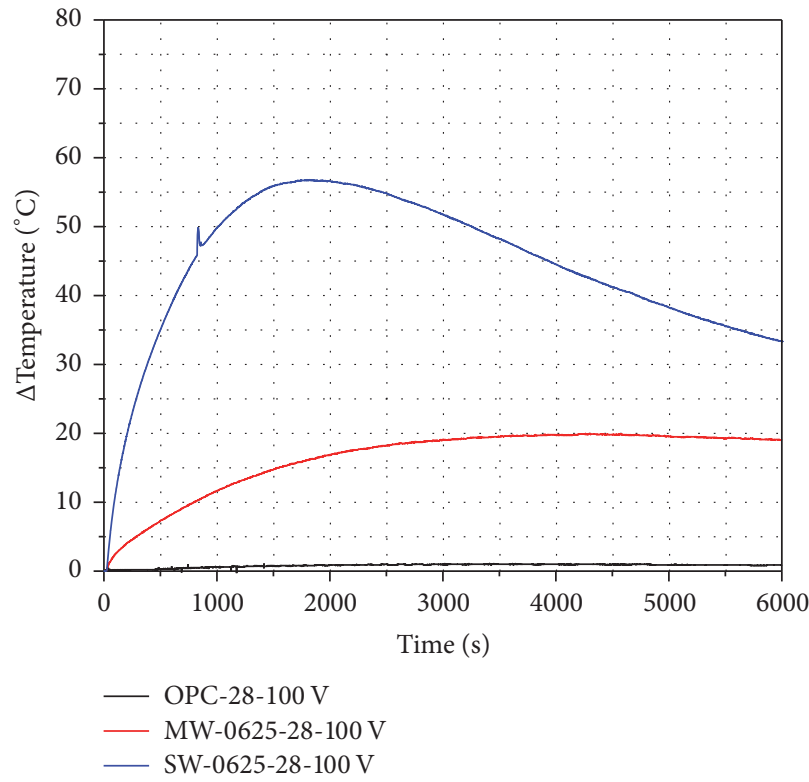

(a) $0.0625 \mathrm{wt} \%$ content

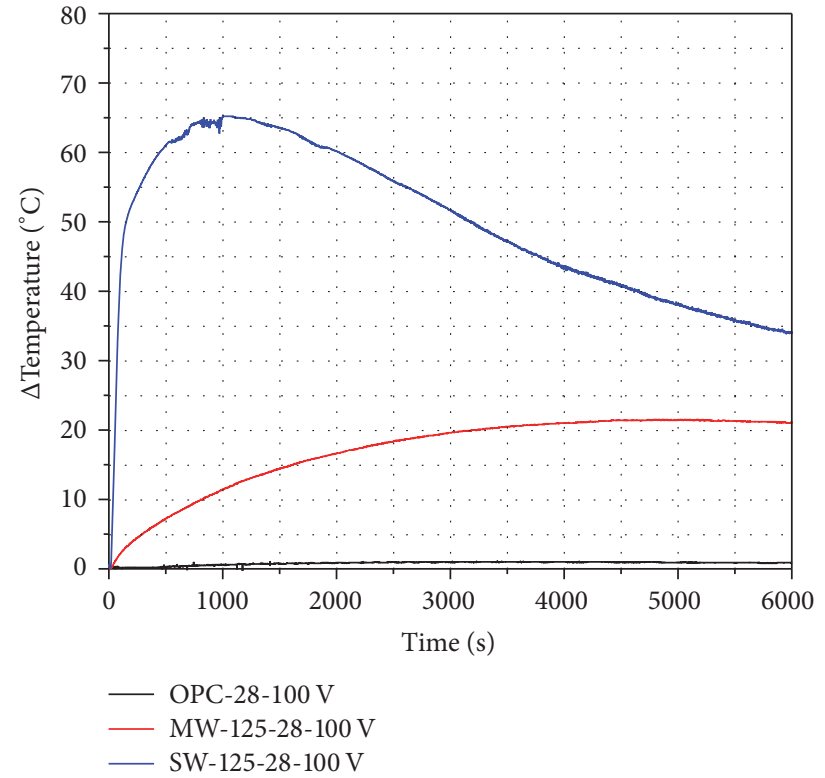

(b) $0.125 \mathrm{wt} \%$ content

FIgURE 7: Temperature variations for 28 days of curing and $100 \mathrm{~V}$ of electricity.

cement mortar was $303.7 \%$ higher than that of the 0.125 wt $\%$ MWCNT cement mortar. After curing for 28 days, the effects of temperature variation on the SWCNT and MWCNT cement mortars were significantly improved as the CNT content increased. It can be concluded that the increase in temperature of the SWCNT cement mortar, when supplied with $100 \mathrm{~V}$ of electricity, is over $55^{\circ} \mathrm{C}$. Small cracks propagated around the electrode in the SWCNT cement mortar 


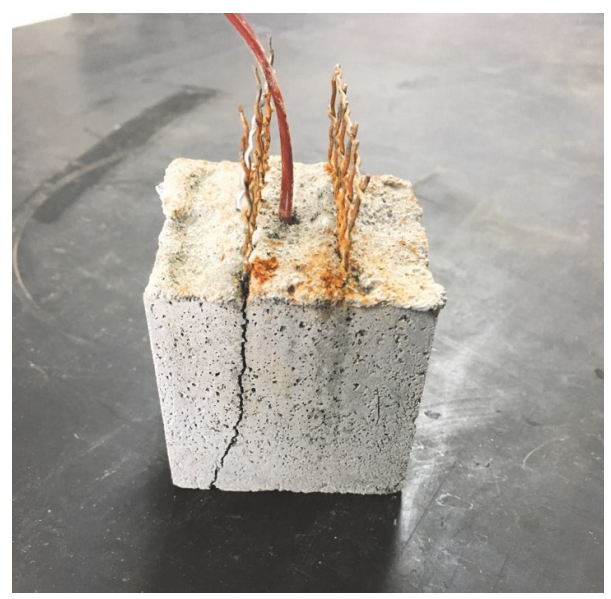

Figure 8: Crack in the SWCNT cement mortar.

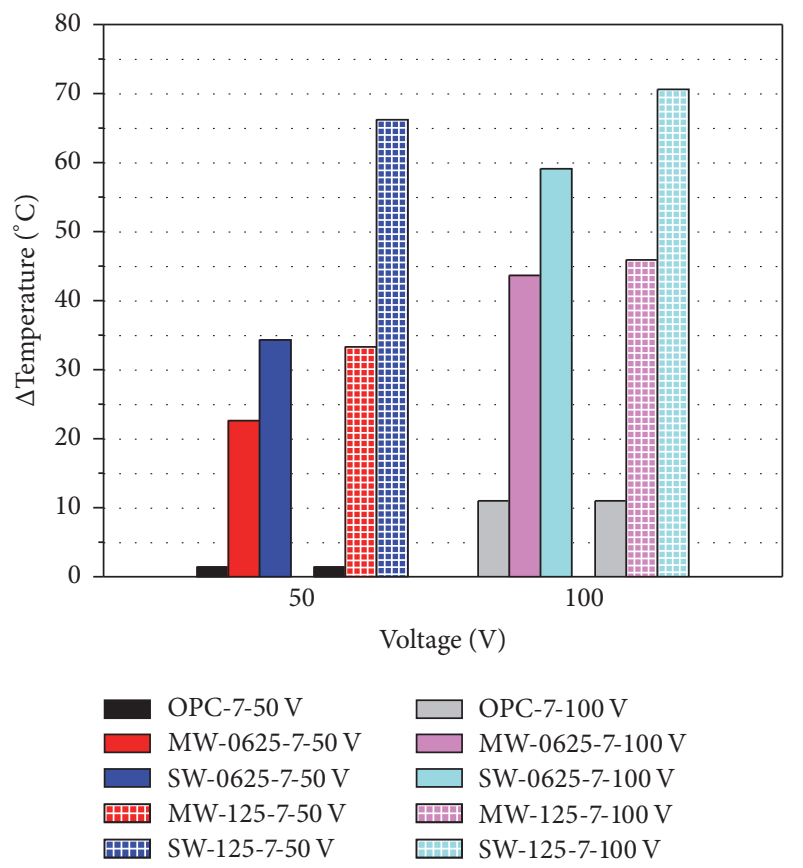

(a) 7-day curing period

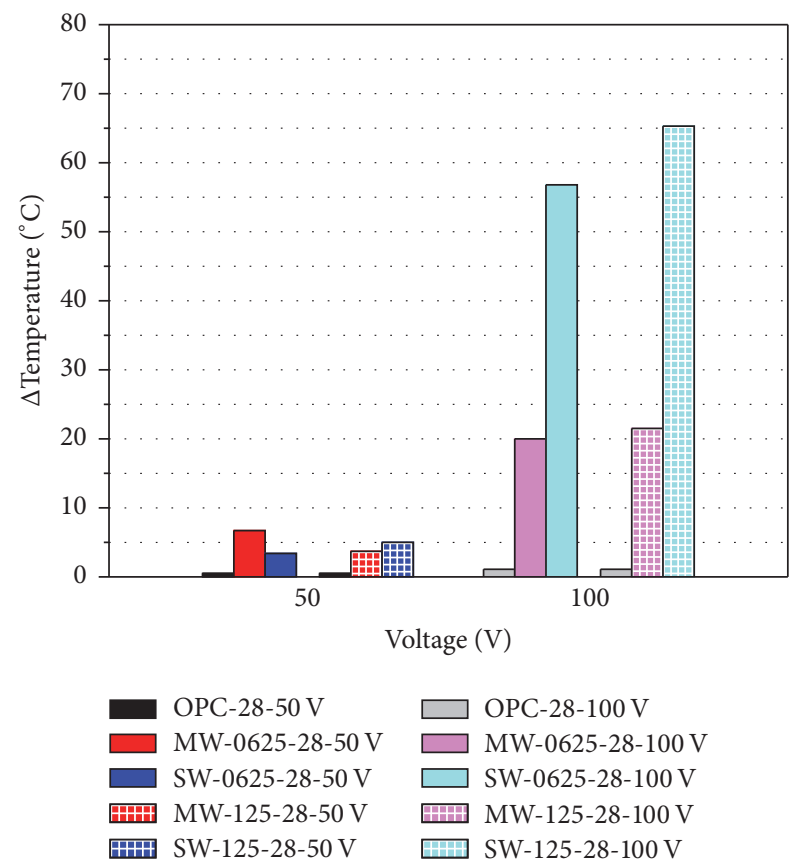

(b) 28-day curing period

FIGURE 9: Temperature variations of cement mortars according to changes in electricity.

specimens due to the increasing temperature, as shown in Figure 8 . This decrease in temperature variation with respect to time was due to the discontinuity of the cracked cement composites.

Figure 9 shows the temperature variations of cement mortars with changes in electricity. The curing ages were divided into 7 day and 28 day periods. Because the curing had insufficiently progressed after 7 days, there was little difference in the temperature for the MWCNT cement mortar under both $50 \mathrm{~V}$ and $100 \mathrm{~V}$. However, the curing lasting for 28 days was sufficiently advanced, resulting in increased temperature differences for the SWCNT and MWCNT cement mortars under $100 \mathrm{~V}$ of electricity. Comparing the cases with $50 \mathrm{~V}$ and $100 \mathrm{~V}$, we note that a larger supplied electricity typically led to larger temperature variations in the cement mortars. We concluded that a minimum of $100 \mathrm{~V}$ of electricity must be supplied after at least 28 days of curing in order to maximize the heating characteristics of cement mortars.

Figure 10 shows the temperature variations of cement mortars with different curing ages. When supplied with $50 \mathrm{~V}$ of electricity, the temperature variation of the standard cement mortar increased by $0.5^{\circ} \mathrm{C}$, showing a minimal temperature variation that was similar to that for 7 days of curing. The temperature of the $0.125 \mathrm{wt} \%$ SWCNT cement mortar increased by $66.2^{\circ} \mathrm{C}$, while that of the $0.125 \mathrm{wt} \%$ MWCNT cement mortar increased by $33.3^{\circ} \mathrm{C}$, indicating a different trend compared to the 7-day curing specimens. When aged for 7 days, the normal cement mortar was not 

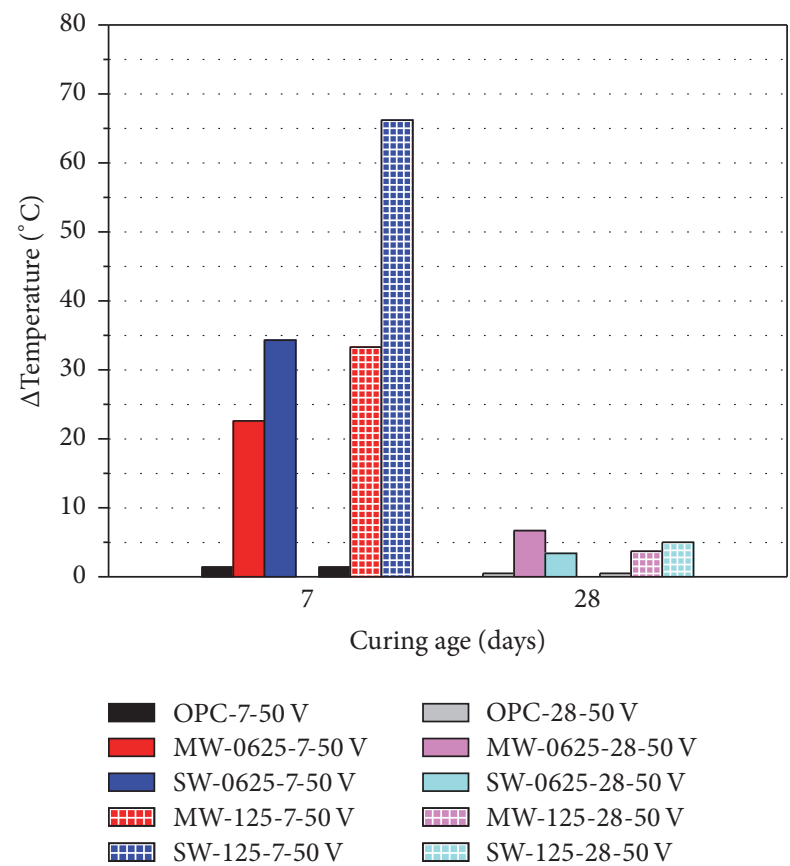

(a) $50 \mathrm{~V}$
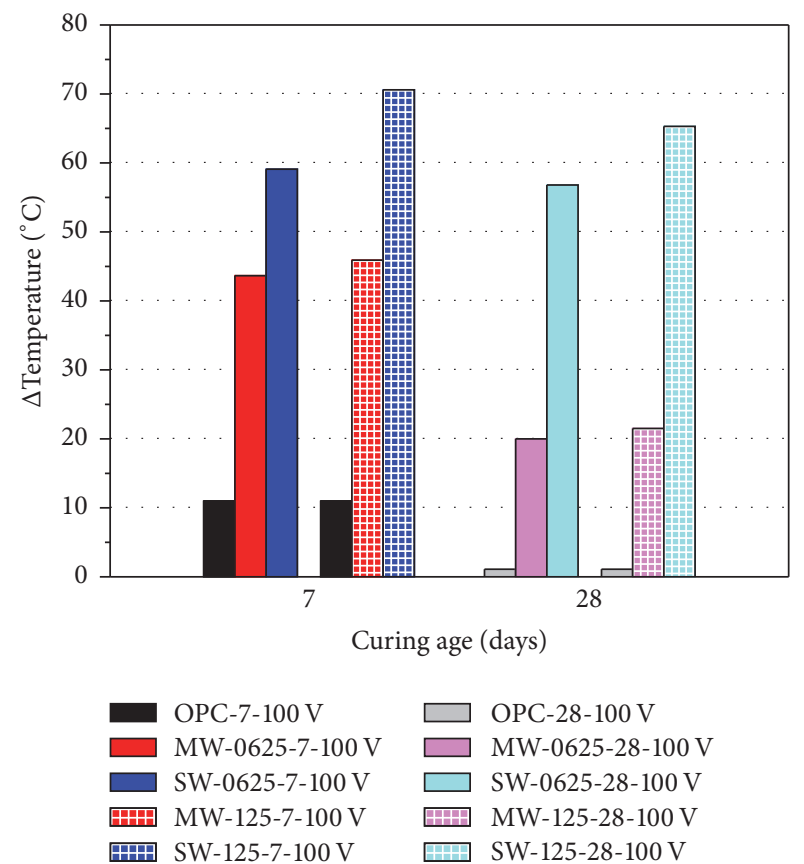

(b) $100 \mathrm{~V}$

FIGURE 10: Temperature variations of cement mortars according to changes in curing age.

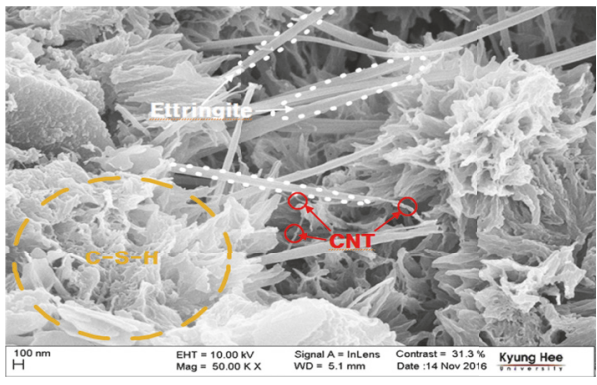

(a) MWCNT cement mortar

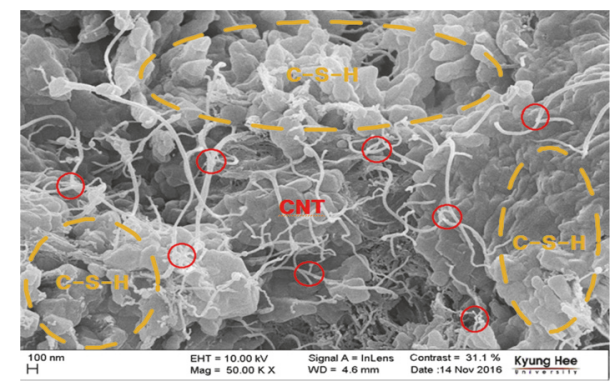

(b) SWCNT cement mortar

FIGURE 11: SEM images of the CNT cement mortars.

completely cured and had only partial heating characteristics. However, all CNT cement mortars with modified heating characteristics had noticeably higher temperature variations. The 28 day curing process resulted in sufficient curing, thus lowering the electrical conductivity of all cement mortars. As a result, the internal temperatures of the cement mortars did not change when supplied with $50 \mathrm{~V}$ of electricity. Overall, applying electricity of less than $50 \mathrm{~V}$ after 28 days of curing for the SWCNT and MWCNT cement mortars led to poor heating characteristics for the CNT cement mortars, regardless of CNT type. When applying $100 \mathrm{~V}$ of electricity, the effects of temperature variation on the SWCNT cement mortars were more significant than for the MWCNT cement mortars.

A cross-sectional analysis was conducted using FE-SEM in order to study the effects of CNT type in CNT cement mortars. The magnification for the images was 50,000 times, and the specimen with largest temperature variations was filmed.

Figure 11(a) shows images of the MWCNT cement mortar. The images show that MWCNTs, which appear as thin threads, combined with calcium-silicate-hydrate (C-S-H) or Ettringite to form a straight line. However, this combination of MWCNTs with C-S-H or Ettringite was only partially confirmed, with the combination of C-S-H and Ettringite being more frequently observed. We observe that MWCNTs in water were not evenly dispersed within the MWCNT cement mortar. These images confirm that the heating characteristics of the MWCNT cement mortar were ineffectively modified.

Figure 11(b) shows images of the SWCNT cement mortar. Compared to the MWCNT cement mortar, the comparatively thinner SWCNTs were evenly dispersed and combined with $\mathrm{C}-\mathrm{S}-\mathrm{H}$. Thus, it can be concluded that the excellent physical 
characteristics of SWCNTs lead to more effective changes in the heating characteristics of cement mortars compared to MWCNTs.

\section{Conclusions}

In this study, we conducted heating experiments in order to analyze the heating characteristics of CNT cement mortars produced by mixing SWCNTs and MWCNTs with cement. The temperature variations of CNT cement mortars were analyzed with respect to variations in each parameter, which led to the following conclusions.

(1) In terms of modifying the heat characteristics of cement mortars, mixing SWCNTs is more effective than mixing MWCNTs. It can be concluded that the physical characteristics of SWCNTs lead to more effective variations in the heating characteristics of cement mortars compared to MWCNTs.

(2) According to the heating test results of the SWCNT cement mortar, the larger the CNT content, the larger the temperature change of the cement mortar. By increasing the SWCNT content in cement mortars, the thermal properties of the cement mortars are effectively modified.

(3) The desired modified thermal characteristics for CNT cement mortars are obtained when a higher voltage is applied. In particular, after 28 days of curing, the MWCNT cement mortar had a heat generation of more than $20^{\circ} \mathrm{C}$ when supplied with a voltage of $100 \mathrm{~V}$ or more, while the SWCNT cement mortar had a heat generation of more than $50^{\circ} \mathrm{C}$ when supplied with a voltage of $100 \mathrm{~V}$ or more.

(4) An increasing curing period led to worse heating characteristics for the SWCNT and MWCNT cement mortars. However, SWCNT cement mortar can modify its heating characteristics more strongly after 28 days of curing than MWCNT cement mortar. The reason for this may be the comparatively excellent physical characteristics of SWCNTs compared to MWCNTs.

\section{Conflicts of Interest}

The authors declare that they have no conflicts of interest.

\section{Acknowledgments}

This research was supported by a grant from the Ministry of Land, Infrastructure and Transport of the Republic of Korea (17CTAP-C129720-01) and a grant from the R\&D Program of the Korea Railroad Research Institute.

\section{References}

[1] S. Iijima, "Helical microtubules of graphitic carbon," Nature, vol. 354, no. 6348, pp. 56-58, 1991.
[2] H. Dai, A. G. Rinzler, P. Nikolaev, A. Thess, D. T. Colbert, and R. E. Smalley, "Single-wall nanotubes produced by metalcatalyzed disproportionation of carbon monoxide," Chemical Physics Letters, vol. 260, no. 3-4, pp. 471-475, 1996.

[3] M. Scarselli, P. Castrucci, and M. De Crescenzi, "Electronic and optoelectronic nano-devices based on carbon nanotubes," Journal of Physics: Condensed Matter, vol. 24, no. 31, Article ID 313202, 2012.

[4] K. Sobolev and S. P. Shah, "Self sensing capability of multifunctional cementitious nanocomposites," in Nanotechnology in Construction, pp. 363-369, Springer, 2015.

[5] M. S. Konsta-Gdoutos and C. A. Aza, "Self sensing carbon nanotube (CNT) and nanofiber (CNF) cementitious composites for real time damage assessment in smart structures," Cement and Concrete Composites, vol. 53, pp. 162-169, 2014.

[6] C. Camacho-Ballesta, E. Zornoza, and P. Garcés, "Performance of cement-based sensors with CNT for strain sensing," Advances in Cement Research, vol. 28, no. 4, pp. 274-284, 2016.

[7] J. I. Lee and H. T. Jung, "Technical status of carbon nanotubes composites," Korean Chemical Engineering Research, vol. 46, no. 1, pp. 7-14, 2008.

[8] J. Bharj, "Experimental study on compressive strength of cement-CNT composite paste," Indian Journal of Pure and Applied Physics (IJPAP), vol. 52, no. 1, pp. 35-38, 2015.

[9] A. Chaipanich, T. Nochaiya, W. Wongkeo, and P. Torkittikul, "Compressive strength and microstructure of carbon nanotubes-fly ash cement composites," Materials Science and Engineering A, vol. 527, no. 4-5, pp. 1063-1067, 2010.

[10] A. Cwirzen, K. Habermehl-Cwirzen, and V. Penttala, "Surface decoration of carbon nanotubes and mechanical properties of cement/carbon nanotube composites," Advances in Cement Research, vol. 20, no. 2, pp. 65-73, 2008.

[11] R. Hamzaoui, A. Bennabi, S. Guessasma, M. R. Khelifa, and N. Leklou, "Optimal carbon nanotubes concentration incorporated in mortar and concrete," Advanced Materials Research, vol. 587, no. 10, pp. 107-110, 2012.

[12] B. Krause, M. Mende, P. Pötschke, and G. Petzold, "Dispersability and particle size distribution of CNTs in an aqueous surfactant dispersion as a function of ultrasonic treatment time," Carbon, vol. 48, no. 10, pp. 2746-2754, 2010.

[13] S. Kumar, P. Kolay, S. Malla, and S. Mishra, "Effect of multiwalled carbon nanotubes on mechanical strength of cement paste," Journal of Materials in Civil Engineering, vol. 24, no. 1, pp. 84-91, 2011.

[14] T. Manzur and N. Yazdani, "Optimum mix ratio for carbon nanotubes in cement mortar," KSCE Journal of Civil Engineering, vol. 19, no. 5, pp. 1405-1412, 2015.

[15] M. S. Morsy, S. H. Alsayed, and M. Aqel, "Hybrid effect of carbon nanotube and nano-clay on physico-mechanical properties of cement mortar," Construction and Building Materials, vol. 25, no. 1, pp. 145-149, 2011.

[16] S. Musso, J.-M. Tulliani, G. Ferro, and A. Tagliaferro, "Influence of carbon nanotubes structure on the mechanical behavior of cement composites," Composites Science and Technology, vol. 69, no. 11-12, pp. 1985-1990, 2009.

[17] G. S. Seo, An experimental study on improvement of mechanical strength of nano cementitious composites [M.S. thesis], University of KyungHee, 2016.

[18] H. Choi, D. Kang, G. S. Seo, and W. Chung, "Effect of some parameters on the compressive strength of MWCNT-cement composites," Advances in Materials Science and Engineering, vol. 2015, Article ID 340808, 8 pages, 2015. 
[19] M. D. C. Camacho, O. Galao, F. J. Baeza, E. Zornoza, and P. Garcés, "Mechanical properties and durability of CNT cement composites," Materials, vol. 7, no. 3, pp. 1640-1651, 2014.

[20] S. T. Kang and S. H. Park, "Experimental study on improving compressive strength of MWCNT reinforced cementitious composites," Journal of the Korea Concrete Institute, vol. 26, no. 1, pp. 63-70, 2014.

[21] J. Gomis, O. Galao, V. Gomis, E. Zornoza, and P. Garcés, "Selfheating and deicing conductive cement. Experimental study and modeling," Construction and Building Materials, vol. 75, pp. 442-449, 2015.

[22] H. Zhao, Z. Wu, S. Wang, J. Zheng, and G. Che, "Concrete pavement deicing with carbon fiber heating wires," Cold Regions Science and Technology, vol. 65, no. 3, pp. 413-420, 2011.

[23] D. D. L. Chung, "Self-heating structural materials," Smart Materials and Structures, vol. 13, no. 3, pp. 562-565, 2004.

[24] B. Han, X. Yu, and J. Ou, "Effect of water content on the piezoresistivity of MWNT/cement composites," Journal of Materials Science, vol. 45, no. 14, pp. 3714-3719, 2010.

[25] B. Han, X. Yu, E. Kwon, and J. Ou, "Effects of CNT concentration level and water/cement ratio on the piezoresistivity of CNT/cement composites," Journal of Composite Materials, vol. 46, no. 1, pp. 19-25, 2012.

[26] Q. Zhang and H. Li, "Experimental investigation on the ice/snow melting performance of CNFP MWCNT/cementbased deicing system," Advanced Smart Materials and Smart Structures Technology, pp. 25-26, 2011.

[27] H. K. Kim, I. W. Nam, and H. K. Lee, "Enhanced effect of carbon nanotube on mechanical and electrical properties of cement composites by incorporation of silica fume," Composite Structures, vol. 107, pp. 60-69, 2014.

[28] J. Jose, S. K. De, M. A.-A. A. Maadeed et al., "Compatibilizing role of carbon nanotubes in poly(vinyl alcohol)/starch blend," Starch, vol. 67, no. 1-2, pp. 147-153, 2015.

[29] KSL, "Methods of testing cements-determination of strength," Tech. Rep. ISO679, Korean Standards Association, 2011.

[30] ASTM, "Standard test method for compressive strength of hydraulic cement mortars (Using 2-in, or [50-mm] cube specimens)," Tech. Rep. C109, ASTM International.

[31] KSL, Portland Cement 5201, Korean Standards Association, 2016. 

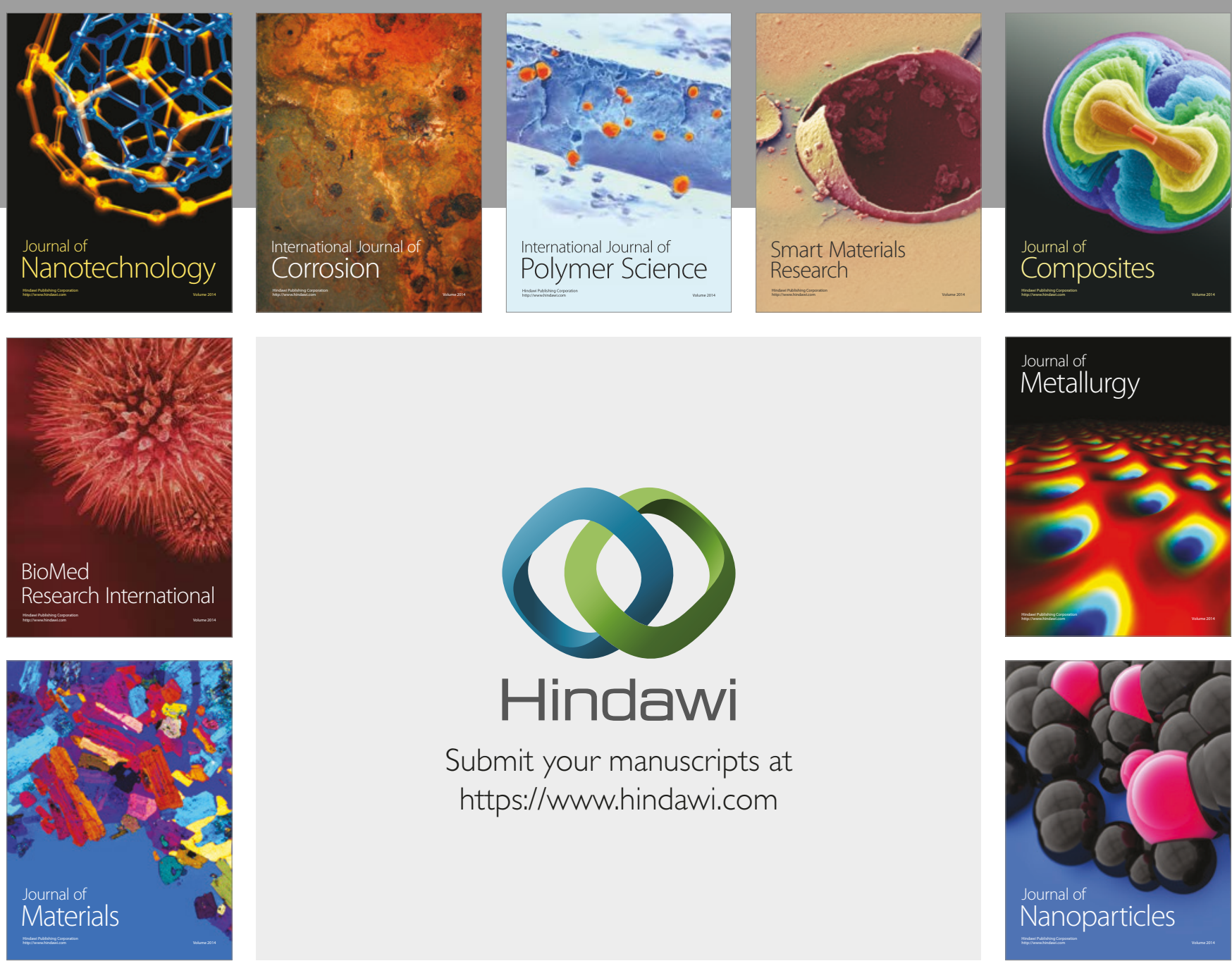

\section{Hindawi}

Submit your manuscripts at

https://www.hindawi.com
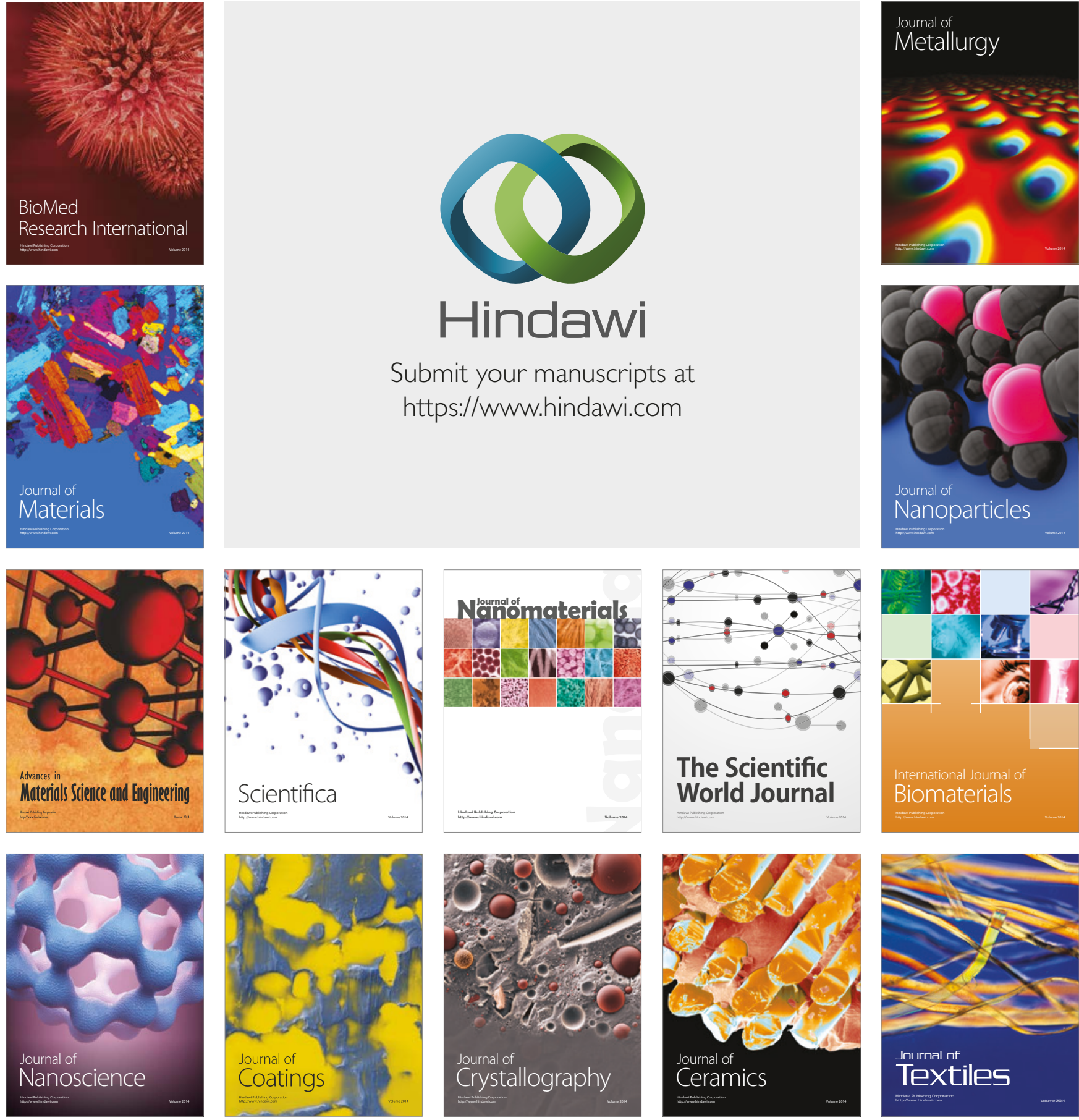

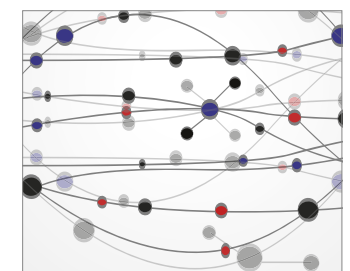

The Scientific World Journal
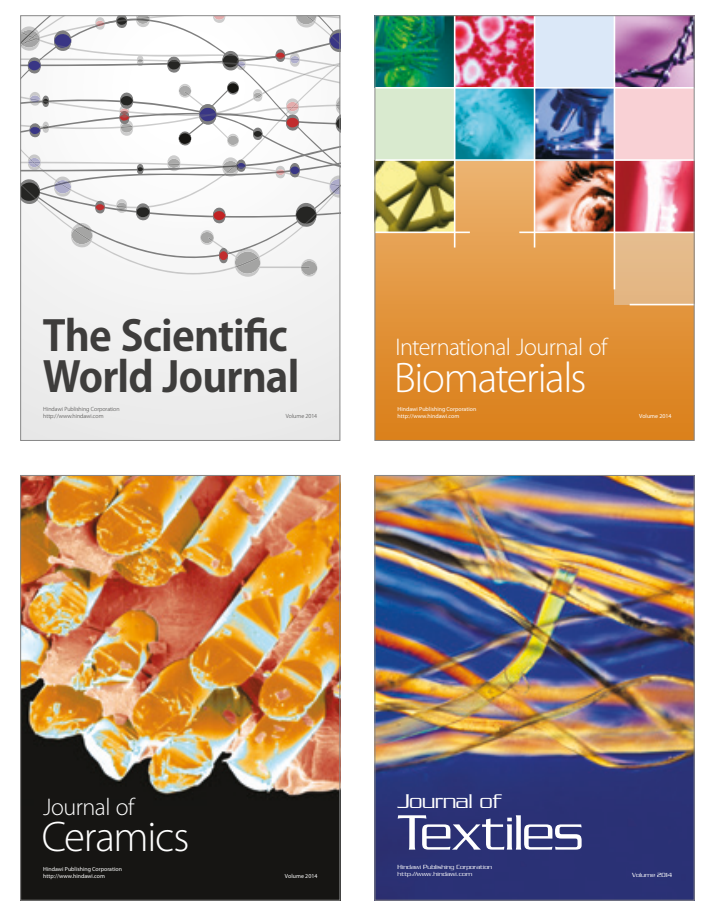